\title{
A Fuzzy Analytic Hierarchy Approach for Ranking and Prioritizing Sustainability Criteria and Indicators of Ecotourism Management
}

\author{
Marzieh Fallah ${ }^{1}$, Ahmad Makmom $^{2}$, Azlizam Aziz $^{3}$, Bose M.M. ${ }^{2}$, \\ AbdullahiAdamu ${ }^{1}$, Mazlina J. ${ }^{3}$, MandeHosea ${ }^{2}$, Azadeh Ghadimzadeh ${ }^{2}$, Shadi \\ K.M. ${ }^{1}$ \\ ${ }^{1}$ Faculty of environmental studies, Department of Environmental management and planning, Universiti Putra \\ Malaysia, 43400, Selangor, Malaysia \\ ${ }^{2}$ Faculty of environmental studies, Department of Environmental Science, Universiti Putra Malaysia, 43400, \\ Selangor, Malaysia \\ ${ }^{3}$ Faculty of Forestry, Universiti Putra Malaysia,Department of Recreation and Ecotourism, 43400, Selangor, \\ Malaysia
}

\begin{abstract}
Ecotourism is an approach that should be environmentally, socially and economically sustainable. For this reason, monitoring and evaluating the ecotourism destination is very important. A good practice is using an indicator system for planning and applying ecotourism models that emphasis on the sustainability approach. Ranking and prioritising of sustainabilitycriteria and indicators facilitates evaluating the situation of the destination by managers. The purpose of this study was to prioritizing and ranking the sustainability criteria and indicators for monitoring and assessment of ecotourism management in Penang National Park, Malaysia. A Fuzzy Analytic hierarchical process (FAHP) was used for prioritizing 9 criteria and 21 indicators from four dimensions of 'ecological', 'social', 'economic' and 'institutional' which obtained from a modified Delphi survey. Five experts from academic and non-academics had provided their judgment for the prioritizing process.Ecological dimension had the highest priority and institutional dimension had the least priority. Conservation of biodiversity, community economic improvement and visitor safety had the highest priorityin the ecological, economic and social dimensions respectively. Prioritised criteria and indicator in this study can help managers and stakeholders in monitoring decision making of different sustainability issues in the national park.
\end{abstract}

Keywords: Criteria and indicators, Fuzzy Analytic Hierarchical Process, Sustainability, Ecotourism

\section{Introduction}

Ecotourism has grown steadily over the last few years [1,2] recording a growth rate of $10-125 \%$ annually. i.e., $300 \%$ faster than the average growth rate for the whole tourism industry [3] and the major players are mostly developing countries with flora and fauna that are both rare and under threat and endangered that see ecotourism as a great opportunity for economic development through sustainable development $[4,5]$.

However, in recent years, ecotourism has faced some challenges, especially since the notion of ecotourism is still to be adequately defined while guidelines about which opportunities are involved as ecotourism, and which are not have still to be formulated [6]. When ecotourism management is poor, it will damage the resources [7, 8]. Thus, ecotourism is not an opportunity but it will be a challenge for the sustainability of the destination area [9]. At this way ecotourism will act like mass tourism which destroys the resources with a lees speed [10]. Usually ecotourism takes place in sensitive areas, which have a little or no infrastructure and they cannot tolerate even a modest degree of usage [11]. Previous studies also indicate significant shortcomings in the field, including equity disparities in local income and employment; dilution of local culture; limited revenue accruing to the destination country, protected area and local communities; and loss of economic diversity $[12,13]$.Criteria and indicators can provide a complete overview of the ecological and structural condition of the region [14], also they recognize and assess the subjects that must be considered to progress the degree of sustainability of destination area. [15]. Indicators can be used for a wide area from science based monitoring and assessment to the management level [16-18].

Mäkelä, et al. [19] stated that the connection between indicators and the state of the stand is not clear, and that important causal links between the indicators have not been appreciated. The ontology of an indicator system is obvious in its multi-level grouping system. In most criteria and indicator systems criteria head the hierarchy. Each is usually related to multiple indicators at lower levels that should ideally monitor development in meeting it [20]. 
Therefore, the focus of this paper will be in applying the FAHP for ranking and prioritizing the ecotourism sustainability indicators. Nine (9) criteria and 21 indicators were identified from a modified Delphi in previous studies. Subsequently by using the AHP, which was created by Saaty [21], these set of criteria and indicator were ranked and prioritized.

\subsection{Site description}

Located in the northwest corner of Penang Island, the Penang National Park (PNP) was acknowledged as a national park on 2003 and was also the first protected area, which was legally, gazette under the National Park Act of 1980. This coastal forest has a size of 1266 hectares. Figure 1 shows the location of PNP in Penang Island and in Malaysia.

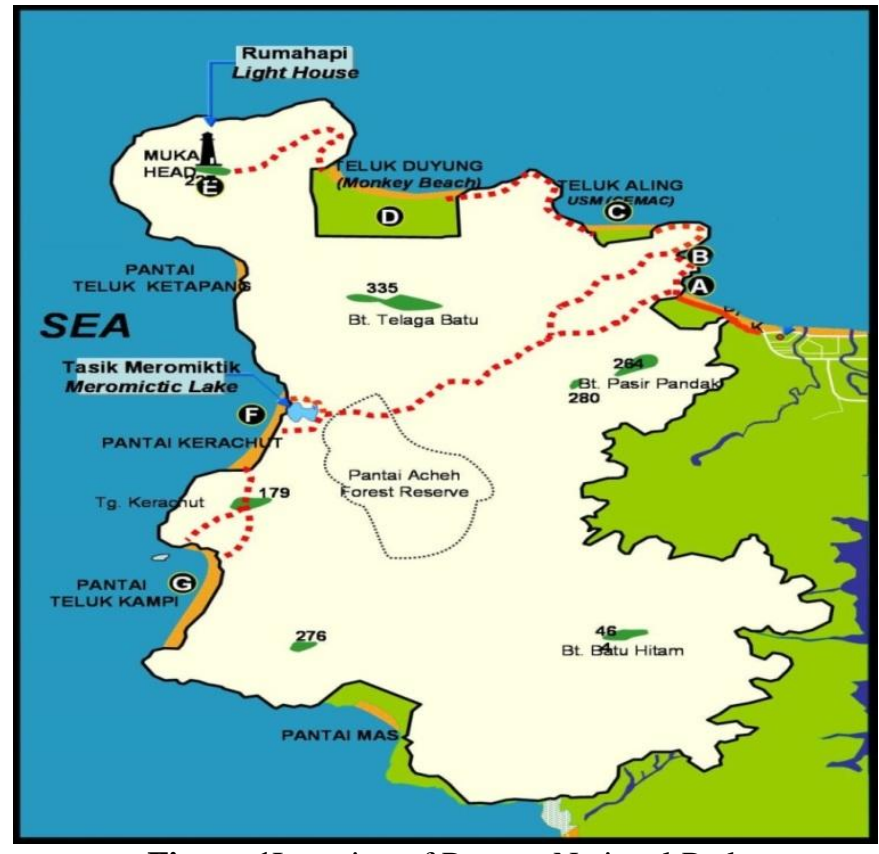

Figure 1Location of Penang National Park

The PNP has some unique features like MeromicticLake, turtle sanctuary and it is also rich in timber as well as medicinal and ornamental plants. These features could be a great potential for the ecotourism activities. [22]. PNP has the potential to be as highlighted spot for ecotourism in Malaysia.According to the reports from the Wildlife and National Park Department of Penang National Park, visitor numbers increased from 21,768 in 2004 to 115,915 in 2013 with $4 \%$ growth rate annually. Beside the rapid influx of the visitors the park is facing some challenges, like waste management and flora and fauna loss [22] that can threat the sustainability of the park. For this reason having a set of prioritized criteria and indicators can facilitate the process of monitoring and evaluating of ecotourism activities of the park.

\subsection{Analytic Hierarchy process (AHP)}

\section{Methodology}

In this study, Fuzzy AHP technique was used to prioritize the criteria and indicators of ecotourism management in PNP. Among all Multi Criteria Decision Making (MCDM), AHP is a broadly-used instrument, which was first proposed by Saaty in 1980. AHP is a suitable method for show the decision maker opinions in multifaceted decision making processes [23, 24]. This technique by pairwise comparisons that are calculated using 1-9 scales provides an organised framework for making priorities on each level of hierarchy [25, 26].

For the purpose of structuring a C\&I set, AHP has been found to be the most widely used method [27, 28]. This particular interactive approach making the decision makers capable to inform the analyst of their preferences and to support deliberation of the results $[29,30]$. The principle of AHP structurally comprises a series of "pair-wise comparisons" that are employed for the comparison of criteria and alternatives and principle to one another [21].

Furthermore the method is applicable for the allocation of priorities to the criteria along with the indicators [30,31]. On the other hand, apart from the applied method, other ways of combining information are available when there are several individual judgments from individual stakeholders [32]. Therefore, integration of each judgment must meet the mutual conditions for judgements [33]. Thus, it has been frequently proposed that a geometric mean is used to reflect an average ration [34-36]. When applying AHP, elements are considered 
into separate subdivisions based on a user-defined measurement of similarity. Experts will be asked to do comparisons between similar elements based on a scale of $1-9$ ( 1 being equally important, 9 being extremely more important).

Essentially, decision makers must break down the goal of the decision process into its component from the general to the specific perspective. Usually this structure must contain a goal, criteria and alternative levels, to make a hierarchy. At that time criterion, sub-criterion or alternative) would then be further divided into a proper level of detail. After structuring the hierarchy, priority of each element in the hierarchy would be judged by the experts through pairwise comparisons in structured matrices [37].

\subsection{Fuzzy Analytic Hierarchical Process (FAHP)}

For conducting the FAHP, a Pair-wise comparisonquestionnaire was prepared to translates the preferences of human (i.e., numbers 3, 5, 7, and 9 indicates 'generally important', 'strongly important', 'very important', and 'absolutely important'; and 2, 4, 6, and 8 for compromises between 3, 5, 7, and 9). Therefore, the AHP applies only absolute scale numbers for decisions and for their consequential priorities. While the separate scale of AHP has the benefits of easiness and simplicity of application, it is not adequate to consider the vagueness related to the human's perception regarding to a number. Despite the fact that AHP is well-known and it is easy to understand, this technique is frequently critiqued for its incapability to sufficiently handle the inherent vagueness and uncertainty related to the decision maker's mind mapping.

Human decisions in AHP are signified as absolute numbers. Yet, in numerous real circumstances, the preference model by human the human preference model is ambiguous and experts might be unwilling or incapable of allocating absolute numerical values to the comparison decisions [38]. As long as some criteria are subjective and qualitative, is difficult for the decision makers to reflect their opinion by exact numerical scale.

In order to handle such uncertainties, Integration of Triangular Fuzzy Numbers (TFNs) and AHP as Fuzzy AHP approach assists the decision making on subjective valuations. In Fuzzy AHP linguistic judgments in TFNs structured in fuzzy pair-wise comparison matrices are then used to determine the related weights of substances and prioritizing of elements.

Numerous fuzzy AHP approaches have been recommended by numerous authors in literatures. The first studies that used fuzzy logic principle to AHP were suggested by [39]. Buckley [40] introduced trapezoidal fuzzy numbers to indicate the decision maker's evaluation on options regarding each criterion; however Van Laarhoven and Pedrycz [39] used triangular fuzzy numbers. Deng [41] offered a fuzzy method for tackling qualitative multi-criteria analysis issues in a direct and simple way.

Many procedures have been used to manage comparison matrices [40, 42-44] such as Chang's method (1996), which is broadly used because it is easy to apply for the purpose of computing relative weights. However, there are some challenges with this approach which could result in erroneous criteria and alternatives being wrongly ranked [45]. A fuzzy set, $\tilde{\mathrm{A}}$, is defined by its membership functions which reflect the grading of any element $\mathrm{x}$ of $\mathrm{X}$ that has partial membership of $\mathrm{A}$. Triangular fuzzy number is commonly employed as a membership function as it is computationally efficient. The values of membership function range from 0 to 1 .

If element $\mathrm{x}$ belongs $\tilde{\mathrm{A}}, \Omega_{\tilde{\mathrm{A}}}(\mathrm{x})=1$ and clearly not $\bigcap_{\tilde{\mathrm{A}}}(\mathrm{x})=0$.

A triangular fuzzy number could be represented as $(1, \mathrm{~m}, \mathrm{u})$ where the parameters $\mathrm{l}, \mathrm{m}$, and $\mathrm{u}$ indicate the lower bound value, the modal value, and the upper bound value, respectively, that define a fuzzy result in equation (1) and Figure 2, [46].

$\nabla_{A}(x)=\left\{\begin{array}{cc}0, & x<1, \\ (x-1) /(m-1), & 1 \leq x \leq m, \\ (u-x) /(u-m), & m \leq x \leq u, \\ 0, & x>u\end{array}\right\}$

Thus, the triangular type membership function is as follows: 


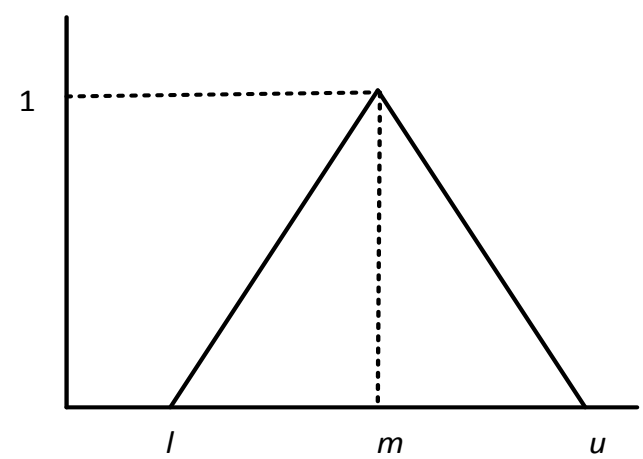

Figure 2Triangular Fuzzy Number

The Number of Pairwise Comparisons: In an election with $\mathrm{N}$ candidates, the overall number of pairwise comparisons is shown in Eq. (2):

$(\mathrm{N}-1) \mathrm{N} / 2$

The research framework for Fuzzy AHP in this study is illustrated in Figure 3.

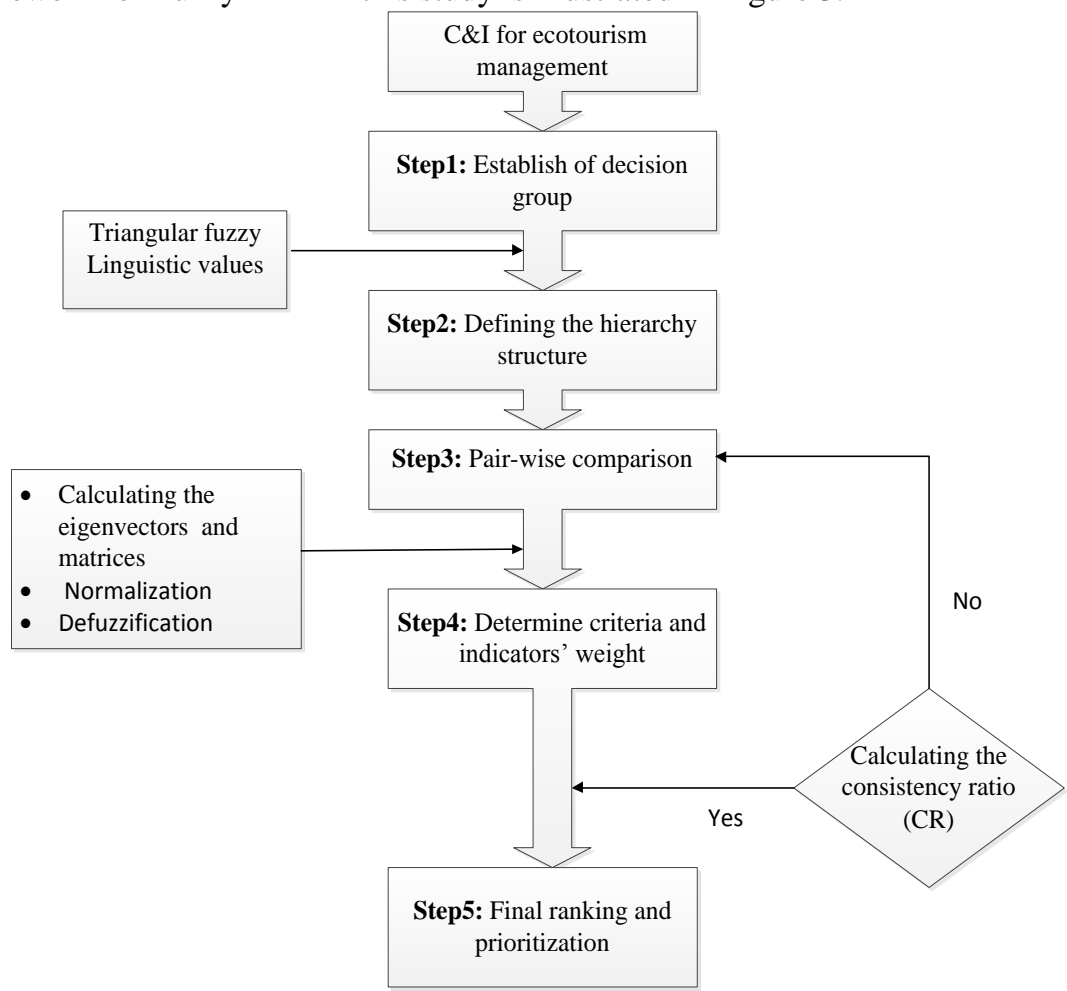

Figure 3Research framework for FAHP of the study

\subsection{Questionnaire survey for FAHP}

With the purpose of weighing the criteria and indicators, a questionnaire was designed and distributed to ecotourism and sustainable tourism specialists. Five completed surveys were submitted and the results were analysed. The questionnaire was designed in a way that the participants could choose their preferences in the criteria and indicators for ecotourism management in the Penang National Park. The participants delivered consistent facts for the study. Based on the fuzzy numbers priorities of the criteria and indicators were determined by a panel of experts. The elements in one level with regard to their influence or importance to the elements of next higher level were examined by pairwise comparison. The input matrix of pairwise comparisons indicates the degree to which an element is prioritized compared to the other, or its comparative prominence and influence with regard to the element of the level above. Generally, the pair wise comparisons are articulated in a scale between one (giving equal importance) to nine (gives different degrees of importance from weak to extreme). A triangular Linguistic judgement is illustrated in Table 1.

Table 1 Triangular Linguistic judgment (lee et. all 2008) 


\begin{tabular}{|c|l|c|c|c|c|c|c|}
\hline Value & \multicolumn{1}{|c|}{ Linguistic scale } & \multicolumn{3}{|c|}{ Triangular Fuzzy scales } & \multicolumn{3}{c|}{ Triangular Fuzzy reciprocal scale } \\
\hline 1 & Equally Preferred & 1 & 1 & 1 & 1 & 1 & 1 \\
\hline 2 & Intermediate & 1 & 2 & 3 & 0.333 & 0.5 & 1 \\
\hline 3 & moderately Preferred & 2 & 3 & 4 & 0.25 & 0.333 & 0.5 \\
\hline 4 & Intermediate & 3 & 4 & 5 & 0.2 & 0.25 & 0.333 \\
\hline 5 & Strongly Preferred & 4 & 5 & 6 & 0.166 & 0.2 & 0.25 \\
\hline 6 & Intermediate & 5 & 6 & 7 & 0.142 & 0.16 & 0.2 \\
\hline 7 & very strongly Preferred & 6 & 7 & 8 & 0.125 & 0.142 & 0.166 \\
\hline 8 & Intermediate & 7 & 8 & 9 & 0.111 & 0.125 & 0.142 \\
\hline 9 & Extremely Preferred & 9 & 9 & 9 & 0.111 & 0.111 & 0.111 \\
\hline
\end{tabular}

After collecting all respondents' opinion with triangular fuzzy numbers with using the fuzzy average we aggregate all experts' opinion. For calculating the fuzzy average for $\mathrm{N}$ respondents we use equation (3):

$\mathrm{F}_{\mathrm{i}}=\left(\mathrm{l}_{\mathrm{i}}, \mathrm{m}_{\mathrm{i}}, \mathrm{u}_{\mathrm{i}}\right)$

$$
\text { fuzzyaverage }=\left[\frac{l_{1}+l_{2}+\ldots+l_{n}}{n}, \frac{m_{1}+m_{2}+\ldots m_{n}}{n}, \frac{u_{1}+u_{2}+\ldots+u_{n}}{n}\right]
$$

With calculating the fuzzy average we can obtain the fuzzy matrices (Table 2). Matrices of economic indicators are illustrated in Table 2:

Table 2Fuzzy average of economic indicators

\begin{tabular}{|l|l|l|l|l|l|l|l|l|l|l|l|l|}
\hline & \multicolumn{3}{|l}{ Ind7.1 } & \multicolumn{3}{l}{ Ind7.2 } & \multicolumn{1}{l}{ Ind8.1 } & \multicolumn{3}{l|}{ Ind8.2 } \\
\cline { 2 - 14 } & 1 & $\mathrm{~m}$ & $\mathrm{u}$ & 1 & $\mathrm{~m}$ & $\mathrm{u}$ & 1 & $\mathrm{~m}$ & $\mathrm{u}$ & 1 & $\mathrm{~m}$ & $\mathrm{u}$ \\
\hline Ind7.1 & 1.00 & 1.00 & 1.00 & 1.70 & 2.23 & 2.79 & 2.40 & 3.40 & 4.40 & 2.80 & 3.80 & 4.80 \\
\hline Ind7 2 & 0.36 & 0.45 & 0.59 & 1.00 & 1.00 & 1.00 & 2.09 & 2.72 & 3.38 & 1.51 & 2.04 & 2.60 \\
\hline Ind8.1 & 0.23 & 0.29 & 0.42 & 0.30 & 0.37 & 0.48 & 1.00 & 1.00 & 1.00 & 1.68 & 2.20 & 2.73 \\
\hline Ind8.2 & 0.21 & 0.26 & 0.36 & 0.38 & 0.49 & 0.66 & 0.37 & 0.45 & 0.59 & 1.00 & 1.00 & 1.00 \\
\hline
\end{tabular}

\section{Results and discussions}

NineCriteria and 21 indicators were obtained from four rounds of Delphi technique. These C\&I are from different dimension of sustainable development namelyecological, social, economic, and institutional. Three criteria for ecological dimension, 3criteria for social dimension, 2 criteria for economic dimension and 1 institutional dimension has been identified from a modified Delphi technique. Sevenindicators for ecological dimension, 8 indicators for social dimension , 4 indicators for economic dimension and finally 2 indicators for institutional dimension has been identified. (Nine criteria consist of 3,3,2,1 and twenty-one indicators consist of 7,8,4,2 identified respectively in different ecological, social, economic, and institutional dimensions). Each dimension, environmental, social, economic, and institutional criteria consists of 5, 5, 3, 3 and 5 sub-criteria, respectively. Identified criteria and indicators are introduced in Figure 4. 


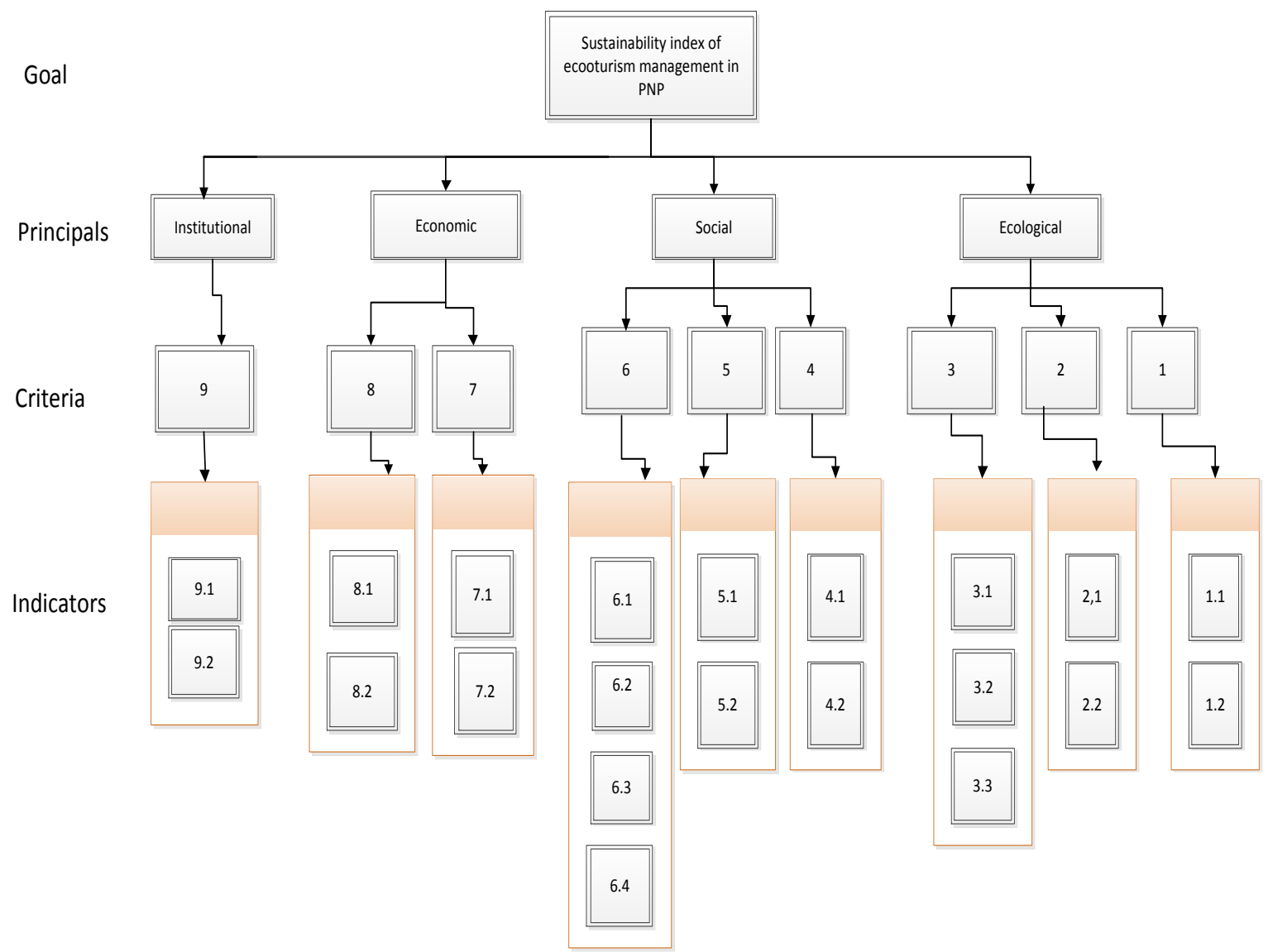

Figure 4Hierarchy of criteria \& Indicators 1. Conservation of biodiversity, 2.Maintenance of Scenic beauty, 3.Environmental Management and practices, 4.Visitor Satisfaction, 5.Visitor safety, 6.Public Education,

7.Community's economic improvement, 8. Financial support, 9.Institutional cooperation. 1.1. Number of threatened species, 1.2. Number of Endemic species, 2.1. Amount of trails and margin degraded, 2.2. Amount of litter \& human waste per sq feet, 3.1.Average number of visitors per day, 3.2.Number of environmental monitoring per year, 3.3.Frequency of assessment of maintenance inspection per year, 4.1.Percentage of satisfied visitors, 4.2. Number of complains reported by visitors, 5.1. Number of reported accidents, 5.2.Number of cases on tourists affected by crime, 6.1. Number of public awareness program for low impact activities, 6.2. Number of trained, skilled and dedicated staff in the park, 6.3.Number of self-guided signage, 6.4.Number of visitors using interpretative center, 7.1. Number of tourism businesses and services operated and owned by the locals, 7.2. Number of available homestays, 8.1.Amount of entrance fee, 8.2.Amount of annual maintenance budget, 9.1.Number of meetings and intellectual discourses with community, stakeholders and, 9.2. Number of stakeholders involved in park's management.

Through FAHP in this study, the indicators were arranged according to their highest priority weights to the lowest priority. Economic, social and environmental dimensions are commonly used in most sustainability works, however, institutional dimensions are considered here as it is viewed as another important part of sustainability. In 1995 indicators for assessing the sustainability improved by UN Commission for Sustainable Development and it was implemented in Agenda 21 (UN, 1996) and Institutional dimension was added as fourth dimension of sustainability [47].

Ecological principle with normal weight of 0.313 has the most priority. Economical principle with normal weight of 0.263 has the second priority. Social principle with normal weight of 0.227 has the third priority. Institutional cooperation principle with normal weight of 0.196 has the forth priority. The result of prioritizing the principles and criteria is tabulated in Table 3. 
Table 3 prioritized principles and criteria

\begin{tabular}{|l|c|}
\hline Principles and Criteria & Priorities \\
\hline Ecological & 0.313 \\
\hline Criteria & \\
\hline Conservation of Biodiversity & 0.503 \\
\hline Maintenance of Scenic beauty & 0.382 \\
\hline Economic & 0.227 \\
\hline Criteria & 0.263 \\
\hline Community's economic improvement & \\
\hline Financial support & 0.774 \\
\hline Social & 0.306 \\
\hline Criteria & 0.227 \\
\hline Visitor safety & \\
\hline Public Education & 0.589 \\
\hline Visitor Satisfaction & 0.306 \\
\hline Institutional & 0.106 \\
\hline
\end{tabular}

In each environmental management system for developing the environmental policy, identifying the significant environmental issue through prioritization is always a challenge for decision makers. In this study Ecological dimension, E1, with normal weight of 0.313 has the highest priority and Institutional cooperation element, E4, with normal weight of 0.196 has the lowest priority. Among the criteria, Conservation of biodiversity, Visitor safety, and Community's economic improvement are the highest priorities.

And among the indicators, Number of threatened species, Amount of litter and human waste per sq feet, Average number of visitors per day, Number of complaints reported by visitors, Number of reported accidents, Number of visitors using interpretative centre, Number of tourism businesses and services operated and owned by the locals, and Number of stakeholders involved in park's management are the highest priorities.

Barzekar, et al. [48] used AHP for ranking Ecological Indicators for Monitoring Sustainability of ecotourism in Northern Forest, Iran, which one of the nine criteria, the criteria Conservation of Natural resources and biodiversity had the highest priority and Maintenance of sceneries, natural \&physical features had the lowest priority. Larimian, et al. [49] used FAHP for ranking the criteria and indicators of environmental safety of Tehran, Iran. The results showed that area 4 and area 1 had the highest and lowest environmental security rates respectively. [32] applied a Fuzzy Analytical Hierarchy Process (FAHP) to four irrigation projects. The outcome demonstrated that the managerial criterion had the on the highest impact on the project. . The technical, social, economic, and environmental criteria rank next in effectiveness, respectively. Prioritizing result of indicators under each criterion is illustrated in Table 4. 
Table 4 prioritized indicators under each criterion

\begin{tabular}{|c|c|}
\hline Criteria and Indicator & Priorities \\
\hline \multicolumn{2}{|l|}{ Conservation of Biodiversity } \\
\hline Number of threatened species & 0.793 \\
\hline Number of Resident species & 0.207 \\
\hline \multicolumn{2}{|l|}{ Environmental Management and practices } \\
\hline Average number of visitors per day & 0.774 \\
\hline Frequency of assessment of maintenance inspection & 0.226 \\
\hline \multicolumn{2}{|l|}{ Mainte nance of Scenic beauty } \\
\hline Amount of litter and human waste per sq feet & 0.75 \\
\hline amount of trails and margin degraded & 0.25 \\
\hline \multicolumn{2}{|l|}{ Community's economic improvement } \\
\hline $\begin{array}{l}\text { Number of tourism businesses and services operated and } \\
\text { owned by the locals }\end{array}$ & 0.809 \\
\hline Number of available homestays & 0.191 \\
\hline \multicolumn{2}{|l|}{ Financial support } \\
\hline Amount of annual maintenance budget & 0.579 \\
\hline Amount of entrance fee & 0.421 \\
\hline \multicolumn{2}{|l|}{ Visitor safe ty } \\
\hline Number of reported accidents & 0.782 \\
\hline number of cases on tourists affected by crime & 0.218 \\
\hline \multicolumn{2}{|l|}{ Environmental Education } \\
\hline Number of visitors using interpretative center & 0.573 \\
\hline Number of trained, skilled and dedicated staff in the park0.343 & 0.343 \\
\hline Number of public awareness programs for low impact activities & 0.084 \\
\hline \multicolumn{2}{|l|}{ Visitor Satisfaction } \\
\hline Number of complains reported by visitors & 0.782 \\
\hline percentage of satisfied visitors & 0.218 \\
\hline \multicolumn{2}{|l|}{ Institutional coope ration } \\
\hline number of stakeholders involved in park's management & 0.541 \\
\hline $\begin{array}{l}\text { number of meetings and intellectual discourses with } \\
\text { community, stakeholders and managers }\end{array}$ & 0.459 \\
\hline
\end{tabular}

\section{Conclusion}

In this study, it was found thatEcologicaldimension, with normal weight of 0.313 has the highestpriority whileInstitutional cooperation dimension, with normal weight of 0.196 has the least priority. Atthe criteria level, Conservation of biodiversity, Visitor safety, and Community's economic improvementreceivedthe highestpriorities for Ecological, Social and Economic dimensions, respectively. And at the indicators level, Number of threatened species, with normal weight of 0.256 from Ecologicaldimension,Number of trained; skilled and dedicated staff in the parkwith normal weight of 0.208 from Social dimension, Number of tourism businesses and services operated \&owned by the locals, with normal weight of 0.459 for Economic dimension, and Number of stakeholders involved in park's managementwith normal weight of 0.540 from Institutionaldimension have the highest priorities..

Findings from the study will help the park's management to monitor the sustainability of the resources. In specific example like in budget cut situation, findings from this study will make it easier for the management to decide which criteria to focus on while protecting the integrity of the resources. As compared to the other dimensions, the management should also concentrate on maintaining the well-being of flora and fauna in the park (from the ecological point of view). Even in the dimension which received the least priority - institutional, it was implied that the management should encourage involvement from various stakeholders including communities and the non-governmental organizations.

\section{References}

[1]. H. Goodwin, "In pursuit of ecotourism," Biodiversity \& Conservation, vol. 5, pp. 277-291, 1996 
[2]. E. Torquebiau and R. D. Taylor, "Natural resource management by rural citizens in developing countries: innovations still required," Biodiversity and Conservation, vol. 18, pp. 2537-2550, 2009.

[3]. IES, "Fact Sheet: Global Ecotourism. The International Ecotourism Society, Size of Global Ecotourism," 2008.

[4]. J. S. Brooks, M. A. Franzen, C. M. Holmes, M. N. Grote, and M. B. Mulder, "Testing hypotheses for the success of different conservation strategies," Conservation biology, vol. 20, pp. 1528-1538, 2006.

[5]. J. Coria and E. Calfucura, "Ecotourism and the development of indigenous communities: The good, the bad, and the ugly," Ecological Economics, vol. 73, pp. 47-55, 2012.

[6]. B. Sander, "The importance of education in ecotourism ventures: lessons from Rara Avis ecolodge, Costa Rica," International Journal of Sustainable Society, vol. 4, pp. 389-404, 2012.

[7]. Z. Mieczkowski, "Environmental issues of tourism and recreation," University Press of America, Inc, Laham 1995

[8]. M. J. Stabler, "Tourism and sustainability: Principles to practiceCAB International," New York 1997.

[9]. W. Li, "Environmental management indicators for ecotourism in China's nature reserves: A case study in Tianmushan Nature Reserve," Tourism Management, vol. 25, pp. 559-564, 2004.

[10]. T. G. Bauer, Tourism in the Antarctic: opportunities, constraints, and future prospects: Haworth Hospitality Press, 2001.

[11]. R. W. Butler, "Sustainable tourism: A state-of-the-art review," Tourism Geographies, vol. 1, pp. 7-25, 1999.

[12]. M. Honey, "1 5 Setting Standards: Certification Programmes for Ecotourism and Sustainable Tourism," Ecotourism and Conservation in the Americas, p. 234, 2008.

[13]. D. B. Weaver, The encyclopedia of ecotourism: Cabi, 2001.

[14]. A. P. E. van Oudenhoven, K. Petz, R. Alkemade, L. Hein, and R. S. de Groot, "Framework for systematic indicator selection to assess effects of land management on ecosystem services," Ecological Indicators, vol. 21, pp. 110-122, 2012.

[15]. M. Lozano-Oyola, F. J. Blancas, M. González, and R. Caballero, "Sustainable tourism indicators as planning tools in cultural destinations," Ecological Indicators, vol. 18, pp. 659-675, 2012.

[16]. L. A. Franco and G. Montibeller, "Problem structuring for multicriteria decision analysis interventions," Wiley Encyclopedia of Operations Research and Management Science, 2009.

[17]. R. J. Raison, A. G. Brown, and D. W. Flinn, Criteria and indicators for sustainable forest management vol. 7: CABI, 2001.

[18]. B. Wolfslehner and H. Vacik, "Mapping indicator models: From intuitive problem structuring to quantified decision-making in sustainable forest management," Ecological Indicators, vol. 11, pp. 274-283, 2011.

[19]. A. Mäkelä, M. d. Río, J. Hynynen, M. J. Hawkins, C. Reyer, P. Soares, M. van Oijen, and M. Tomé, "Using stand-scale forest models for estimating indicators of sustainable forest management," Forest Ecology and Management, vol. 285, pp. 164-178, 2012.

[20]. A. Grainger, "Forest sustainability indicator systems as procedural policy tools in global environmental governance," Global Environmental Change, vol. 22, pp. 147-160, 2012.

[21]. T. L. Saaty, "How to make a decision: the analytic hierarchy process," interfaces, vol. 24, pp. 19-43, 1994

[22]. C. W. Hong and N. W. Chan, "Strength-weakness-opportunities-threats Analysis of Penang National Park for Strategic Ecotourism Management," World Applied Sciences Journal, vol. 10, pp. 136-145, 2010.

[23]. A. Awasthi and S. S. Chauhan, "Using AHP and Dempster-Shafer theory for evaluating sustainable transport solutions," Environmental Modelling \& Software, vol. 26, pp. 787-796, 2011.

[24]. L. Gao and A. Hailu, "Ranking management strategies with complex outcomes: An AHP-fuzzy evaluation of recreational fishing using an integrated agent-based model of a coral reef ecosystem," Environmental Modelling \& Software, vol. 31, pp. 3-18, 2012.

[25]. R. Joshi, D. K. Banwet, and R. Shankar, "A Delphi-AHP-TOPSIS based benchmarking framework for performance improvement of a cold chain," Expert Systems with Applications, vol. 38, pp. 10170-10182, 2011.

[26]. T. L. Saaty, "The analytic Hierarchy process. ," McGrow-Hill, New York, 1980.

[27]. G. A. Mendoza, P. Macoun, R. Prabhu, D. Sukadri, H. Purnomo, and H. Hartanto, Guidelines for applying multi-criteria analysis to the assessment of criteria and indicators. Bogor, Indonesia: CIFOR, 1999.

[28]. B. Wolfslehner and H. Vacik, "Evaluating sustainable forest management strategies with the Analytic Network Process in a Pressure-State-Response framework," Journal of Environmental Management, vol. 88, pp. 1-10, 2008.

[29]. B. Wolfslehner, H. Vacik, and M. J. Lexer, "Application of the analytic network process in multi-criteria analysis of sustainable forest management," Forest Ecology and Management, vol. 207, pp. 157-170, 2005.

[30]. W. Proctor, "Towards sustainable forest management an application of multi-criteria analysis to Australian forest policy," in Third International Conference of the European Society for Ecological Economics, Vienna Austria, 2000.

[31]. G. A. Mendoza and R. Prabhu, "Development of a methodology for selecting criteria and indicators of sustainable forest management: a case study on participatory assessment," Environmental Management, vol. 26, pp. 659-673, 2000.

[32]. A. Montazar, O. N. Gheidari, and R. L. Snyder, "A fuzzy analytical hierarchy methodology for the performance assessment of irrigation projects," Agricultural Water Management, vol. 121, pp. 113-123, 2013.

[33]. E. Forman and K. Peniwati, "Aggregating individual judgments and priorities with the analytic hierarchy process," European Journal of Operational Research, vol. 108, pp. 165-169, 1998.

[34]. G. Jalilova, C. Khadka, and H. Vacik, "Developing criteria and indicators for evaluating sustainable forest management: A case study in Kyrgyzstan," Forest Policy and Economics, vol. 21, pp. 32-43, 2012.

[35]. J. Aczel and F. S. Roberts, "On the possible merging functions," Mathematical Social Sciences, vol. 17, pp. $205-243,1989$.

[36]. J. Aczél and T. L. Saaty, "Procedures for synthesizing ratio judgements," Journal of mathematical Psychology, vol. 27, pp. 93-102, 1983.

[37]. A. Calabrese, R. Costa, and T. Menichini, "Using Fuzzy AHP to manage Intellectual Capital assets: An application to the ICT service industry," Expert Systems with Applications, vol. 40, pp. 3747-3755, 2013.

[38]. C. Kahraman, U. Cebeci, and Z. Ulukan, "Multi-criteria supplier selection using fuzzy AHP," Logistics Information Management, vol. 16, pp. 382-394, 2003.

[39]. P. Van Laarhoven and W. Pedrycz, "A fuzzy extension of Saaty's priority theory," Fuzzy Sets and Systems, vol. 11, pp. 199-227, 1983.

[40]. Buckley, "Fuzzy hierarchical analysis," vol. 17, pp. 233-247, 1985.

[41]. H. Deng, "Multicriteria analysis with fuzzy pairwise comparison," International Journal of Approximate Reasoning, vol. 21, pp. 215-231, 1999.

[42]. Y. M. Wang and K. S. Chin, "Fuzzy analytic hierarchy process: A logarithmic fuzzy preference programming methodology," International Journal of Approximate Reasoning, vol. 52, pp. 541-553, 2011.

[43]. D.-Y. Chang, "Applications of the extent analysis method on fuzzy AHP," European Journal of Operational Research, vol. 95, pp. 649-655, 1996. 
[44]. S.-H. Lee, "Using fuzzy AHP to develop intellectual capital evaluation model for assessing their performance contribution in a university," Expert Systems with Applications, vol. 37, pp. 4941-4947, 2010.

[45]. T.-C. Wang and Y.-H. Chen, "Applying fuzzy linguistic preference relations to the improvement of consistency of fuzzy AHP," Information Sciences, vol. 178, pp. 3755-3765, 2008

[46]. J. Cho and J. Lee, "Development of a new technology product evaluation model for assessing commercialization opportunities using Delphi method and fuzzy AHP approach," Expert Systems with Applications, vol. 40, pp. 5314-5330, 2013.

[47]. S. Pfahl, "Institutional sustainability," International journal of sustainable development, vol. 8, pp. 80-96, 2005.

[48]. G. Barzekar, Azlizam Aziz, M. Mariapan, M. H. Ismail, and S. M. Hosseni, "Using analytical hierarchy process (AHP) for prioritizing and ranking of ecological indicators for monitoring sustainability of ecotourism in northern forest, Iran," Ecologia Balkanica, vol. 3, pp. 59-67, 2011.

[49]. T. Larimian, Z. S. S. Zarabadi, and A. Sadeghi, "Developing a fuzzy AHP model to evaluate environmental sustainability from the perspective of Secured by Design scheme - A case study," Sustainable Cities and Society, vol. 7, pp. 25-36, 2013. 